\title{
Evaluation of Paper Straws versus Plastic Straws: Development of a Methodology for Testing and Understanding Challenges for Paper Straws
}

\author{
Joseph N. Gutierrez, Aidan W. Royals, Hasan Jameel, Richard A. Venditti, and \\ Lokendra Pal *
}

\begin{abstract}
New alternatives to plastic straws are being considered due to consumer demands for sustainability and recent changes in government policies and regulations, such as bans on single-use plastic products. There are concerns regarding paper straw quality and stability over time when in contact with beverages. This study evaluated the performance and properties of commercially available paper straws and their counterpart plastic straws in various intended applications. The physical, mechanical, and compositional characteristics, as well as the liquid interaction properties of the straws, were determined. The paper straws were composed mainly of hardwood fibers that were hard sized with a hydrophobic sizing agent to achieve a contact angle of $102^{\circ}$ to $125^{\circ}$. The results indicated that all the evaluated paper straws lost $70 \%$ to $90 \%$ of their compressive strength after being in contact with the liquid for less than $30 \mathrm{~min}$. Furthermore, the paper straws absorbed liquid at approximately $30 \%$ of the straw weight after liquid exposure for $30 \mathrm{~min}$. Increased liquid temperatures caused lower compressive strengths and higher liquid uptake in the paper straws. This report provides directions and methods for testing paper straws and defines current property limitations of paper straws relative to plastic straws.
\end{abstract}

Keywords: Paper straws; Plastic straws; Tensile strength; Compressive strength; Longevity

Contact information: Department of Forest Biomaterials, North Carolina State University, Campus Box 8005, Raleigh, NC 27695-8005 USA; *Corresponding author: lokendra_pal@ncsu.edu

\section{INTRODUCTION}

Straws provide a simple solution for drinking beverages more conveniently, which makes straws an excellent example of an item people take for granted. Currently, straws are massively consumed. The estimated disposable plastic straw consumption in the US is between 170 million to 490 million straws per day or 63 billion to 142 billion straws per year (Chokshi 2018).

Since the use of straws dates so far back, an accurate time and place of the first usage are impossible to determine. The earliest evidence of straw use was found in a Sumerian tomb dating back to 3000 B.C. The tomb seal showed two men drinking beer from a jar using a tube made of gold (Thompson 2011). In the 1800s, straws became popular and were made of ryegrass, a biodegradable material, which tended to change the flavor and disintegrate into the drink, leaving sediment at the bottom (Smith 2017). Paper, another biodegradable material, replaced ryegrass to solve these issues. Paper straws were the best option for several decades, but the straws still had one problem: they were not durable enough and lost their physical integrity and compressive strength. Thus, they easily collapsed once wet. 
In the 1960s, the usage of plastic as a novel material changed the paper straw market to a point where no paper straws were produced after 1970 (Smith 2017). Plastics are remarkable materials with a wide variety of properties and are durable, inert, and moldable. The problem arose when plastic became a single-use, disposable material on a daily basis. The world produces more than 400 million tons of plastics every year, and $36 \%$ is destined for single-use materials, such as packaging, which in turn generates 300 million tons of waste (UNEP 2018). Of that amount, only 9\% is recycled, $12 \%$ is incinerated, and the remaining $79 \%$ accumulates in landfills and dumps or is littered in the environment, with half of this amount coming from packaging waste (Geyer et al. 2017).

This amount of waste generates pollution and other environmental problems. Plastic pollution in oceans chokes and entangles sea life. It is also linked to diseases on coral reefs, as well as decreases in the reproduction and population growth of zooplankton (Ocean Conservancy 2017). Plastic products do not biodegrade, and instead, these materials break down into smaller pieces that can be consumed by organisms, putting them at risk (Shah et al. 2008; Eagle et al. 2016). Seabirds, marine turtles, and cetaceans are included among the 267 species most affected by plastic ingestion (Haetrakul et al. 2009; Simmonds 2012; Eagle et al. 2016).

Plastic litter in the ocean has been reported since the early 1970s, but it only started to draw attention from the scientific community in the last 25 years (Andrady 2011). Activism against single-use plastic, particularly plastic straws, started in 2015 after videos arose of a turtle with a plastic straw in its nose and because of media interest in the garbage patch in the Pacific Ocean (Minter 2018). Because of this, cities like Seattle, WA and Berkley, CA and big companies like Starbucks have announced the elimination of plastic straw use in the next few years (Brueck 2018; The Guardian 2018; Wootson 2018). In addition, Starbucks has announced a $\$ 10$ million grant intended for the development of a global solution of a recyclable and compostable cup, claiming that the technology will be open to the public after its development (Starbucks Stories 2018).

It is important to point out that the bans need to take into account (and it is not always the case) people with disabilities, notably if the bendy (plastic) straws are banned, since many of the people depend on bendy straws to drink any beverage (Danovich 2018; Szymkowiak 2018). For this reason, a disposable plastic straw ban cannot merely be the solution to this problem. It is then necessary to have a viable alternative to plastic straws.

These market consumption changes and the increasing demand for more sustainable and environmentally friendly options to plastic have generated several alternative materials in the production of drinking straws (Smith 2017). Metal, glass, or silicon are some of the best alternatives for reusable straws. However, single-use straws made of paper are returning to the market. Even bendable straws made of paper are now available (Aardvark 2019). Several brands, mostly in China, the UK, and the US, have returned to products not seen in more than four decades (Smith 2017; BBC 2018; Sorensen and Reinke 2018).

Paper straws are once again the best option for a disposable straw to drink a beverage without the plastic waste that can last for over 500 years in the environment (UNEP 2018). Nevertheless, paper straws are still not durable enough and typically cost more than their plastic counterparts. They lose their mechanical integrity once they are in contact with a typical beverage, and some brands' straws can change the taste of the drink (Purtill 2018).

The aim of this study was to benchmark properties of paper straw already on the market with common, single-use plastic straws to identify which properties need 
improvement. The tensile and compressive properties as well as their interactions with liquids of commercial paper straws were compared with plastic versions.

\section{EXPERIMENTAL}

\section{Materials}

Four commercial brands of plastic straws and three commercial brands of paper straws were used for this research (names of the brands were excluded). All plastic and paper straws were acquired through Amazon.com, Inc. (Seattle, WA, USA). Common drinking (fountain) water, Coca-Cola (i.e., Coke) (Atlanta, GA, USA), and Chick-fil-A (Atlanta, GA, USA) sweet tea were used as the beverages for the longevity tests. Table 1 describes each sample used.

\section{Table 1. Straw Sample Descriptions}

\begin{tabular}{|c|c|c|c|}
\hline Material & Sample ID & Color/Characteristic & Appearance \\
\hline & Plastic1 & Orange & \\
\hline & Plastic2 & White/Bendable & \\
\hline & Plastic3 & Green & \\
\hline & Plastic4 & Multi-color & \\
\hline \multirow{3}{*}{ Paper } & Paper1 & White & \\
\hline & Paper2 & Brown & \\
\hline & Paper3 & Multi-color & \\
\hline
\end{tabular}

\section{Methods}

The determination of the weight and dimensions of the straw samples was necessary to make a proper comparison between the paper and plastic straws. The weight, length, external diameter, and thickness were measured. In addition, the internal diameter, external area, basis weight, and density of the samples were calculated. A Mettler Toledo analytical balance (PB303-S; Columbus, OH, USA) was used for the weight measurements. All tests and measurements were made under standard conditions $\left(23{ }^{\circ} \mathrm{C}\right.$ and $50 \%$ relative humidity $(\mathrm{RH}))$ using conditioned samples according to the TAPPI T402 
sp-08 standard (2013). The fold endurance test was made with an MIT \#1 Folding Endurance Tester (Tinius Olsen Testing Machine Co., Horsham, PA, USA) in accordance with the TAPPI T511 om-02 standard (2008).

The fiber length of the paper in the straws was measured with a fiber quality analyzer (FQA) (FQA-360; OpTest Equipment Inc., Hawkesbury, Ontario, Canada) according to the TAPPI T271 om-07 standard (2012). The sample disintegration was completed using a pulp disintegrator (TMI 73-18; Testing Machines, Inc., New Castle, DE, USA) using $0.5 \mathrm{~g}$ of paper straw sample in $1 \mathrm{~L}$ of water at $15000 \mathrm{rpm}$ for $10 \mathrm{~min}$.

The mechanical and longevity tests compared the plastic straws with the paper straws. The longevity test replicated a typical usage of these products under controlled conditions. The samples were placed in water at four different initial temperatures $\left(0{ }^{\circ} \mathrm{C}\right.$, $21{ }^{\circ} \mathrm{C}, 48{ }^{\circ} \mathrm{C}$, and $\left.82{ }^{\circ} \mathrm{C}\right)$ and in a cold, carbonated beverage $\left(0^{\circ} \mathrm{C}\right)$. The liquid height was fixed at $2 / 3$ of the paper straw's height. The longevity test exposed samples for different time lengths $(0.5,1.0,2.0,3.0,4.0$, and $6.0 \mathrm{~h})$. For each time length, the entire sample was immediately weighed, and an axial and compression test was performed with the wet samples using the bottom part of the straw.

The paper straw tensile strength was measured based on the TAPPI T494 om-01 standard (2006) using a horizontal tensile tester (TMI 84-56; Testing Machines, Inc., New Castle, DE, USA) with an initial gap of $30 \mathrm{~mm}$. The plastic straw tensile strength was measured based on ASTM D882-12 (2012) with a tensile testing machine (4443; Instron, Norwood, MA, USA) with an initial gap of $25 \mathrm{~mm}$.

The compressive strength for both plastic and paper samples was measured based on ASTM D695-15 (2018) and ASTM D2412-11 (2018) using a tensile testing machine (4443; Instron, Norwood, MA, USA). The axial and radial configuration for compression was tested. A compression speed test of $10 \mathrm{~mm} / \mathrm{min}$ was used for the axial configuration using samples with a length/diameter ratio of 2 . A compression speed test of $1 \mathrm{~mm} / \mathrm{min}$ was used for the radial configuration with a length/diameter ratio greater than 8 .

A surface electro-optics (SEO) contact angle analyzer (Phoenix 300; Surface Electro-Optics Co., Ltd., Suwon City, Gyeonggi-do, Korea) was used to determine the contact angle and the surface tendency of the paper straws to absorb liquid. The angle was measured $10 \mathrm{~s}$ after the drop touched the surface. To control the formation speed of the drop, the software equipment defined the fast speed at 47 and the slow speed at 32 . The drop that formed on the samples took $10 \mathrm{~s}$ for each trial before touching the surface. An industrial needle with a gauge of 27 was used for all tests.

Thirty paper straws of each brand were soaked in $1 \mathrm{~L}$ of water for $24 \mathrm{~h}$ to determine whether materials leached from the paper straws. The water was then analyzed with a portable turbidity meter (2020wi; LaMotte, Chestertown, MD, USA). Turbidity is the measurement of water cloudiness caused by particles suspended in the liquid (World Health Organization 2011), although each measurement method uses different units. For example, the nephelometric turbidity unit (NTU) is used by the Environmental Protection Agency (EPA) standard (Fondriest Environmental, Inc. 2014) and the formazin nephelometric unit (FNU) is used by the ISO standard (Hach 2019). However, these units can be considered equivalent, according to ASTM D6855-17 (2017).

\section{RESULTS AND DISCUSSION}


The length, external diameter, and internal diameter were measured for all straws tested. The thickness shown in Table 2 was calculated. The caliper was measured using a Vernier (Traceable Digital Calipers, Fischer Scientific, Hampton, NH, USA). The results shown in Table 3 were calculated based on these measurements. Despite the different dimensions of the plastic straw samples, the thickness of each sample was similar. The dimensions of the paper straw samples were similar as well, but the apparent density changed between the brands and had a relative difference of approximately $12 \%$.

Table 2. Dimensions and Calculated Properties of Plastic and Paper Straws

\begin{tabular}{|c|c|c|c|c|c|c|}
\hline \multirow{3}{*}{ Material } & Sample ID & $\begin{array}{c}\text { Length } \\
(\mathrm{mm})\end{array}$ & $\begin{array}{c}\text { External } \\
\text { Diameter } \\
(\mathrm{mm})\end{array}$ & $\begin{array}{c}\text { Internal } \\
\text { Diameter } \\
(\mathrm{mm})\end{array}$ & $\begin{array}{c}\text { Thickness } \\
(\text { calculated }) \\
(\mathrm{mm})\end{array}$ & $\begin{array}{c}\text { Caliper } \\
(\text { Vernier }) \\
(\mathrm{mm})\end{array}$ \\
\hline \multirow{4}{*}{ Plastic } & Plastic1 & 250 & 7.57 & 7.04 & 0.27 & 0.21 \\
\cline { 2 - 7 } & Plastic2 & 190 & 6.12 & 6.00 & 0.06 & 0.15 \\
\cline { 2 - 7 } & Plastic3 & 198 & 6.29 & 6.16 & 0.07 & 0.18 \\
\cline { 2 - 7 } & Plastic4 & 299 & 9.92 & 9.49 & 0.21 & 0.21 \\
\hline \multirow{3}{*}{ Paper } & Paper1 (White) & 192 & 6.13 & 5.33 & 0.40 & 0.52 \\
\cline { 2 - 7 } & Paper2 (Brown) & 195 & 6.14 & 5.22 & 0.46 & 0.50 \\
\cline { 2 - 7 } & Paper3 (Color) & 195 & 5.96 & 5.04 & 0.46 & 0.49 \\
\hline
\end{tabular}

Table 3. Calculated Properties of Plastic and Paper Straws

\begin{tabular}{|c|c|c|c|c|c|}
\hline Material & Sample ID & $\begin{array}{c}\text { Area } \Pi \times \\
\mathrm{D} \times \mathrm{L} \\
\left(\mathrm{mm}^{2}\right)\end{array}$ & Weight $(\mathrm{g})$ & Basis Weight $\left(\mathrm{g} / \mathrm{m}^{2}\right)$ & $\begin{array}{c}\text { Density } \\
\left(\mathrm{kg} / \mathrm{m}^{3}\right)\end{array}$ \\
\hline \multirow{4}{*}{ Plastic } & Plastic1 & 5946 & 1.068 & 179.7 & 855.6 \\
\cline { 2 - 6 } & Plastic2 & 3660 & 0.469 & 128.3 & 855.0 \\
\cline { 2 - 6 } & Plastic3 & 3911 & 0.556 & 142.2 & 812.5 \\
\cline { 2 - 6 } & Plastic4 & 9320 & 1.381 & 148.2 & 705.8 \\
\hline \multirow{3}{*}{ Paper } & Paper1 (White) & 3690 & 1.100 & 298.1 & 569.2 \\
\cline { 2 - 6 } & Paper2 (Brown) & 3759 & 1.087 & 289.1 & 579.8 \\
\cline { 2 - 6 } & Paper3 (Color) & 3650 & 1.138 & 311.8 & 637.7 \\
\hline
\end{tabular}

Fiber Quality Analyzer (FQA) Analysis

The FQA results are shown in Table 4. The fiber length and the coarseness indicated that all paper straws were made mainly of hardwood fibers. Hardwood fibers are approximately $1 \mathrm{~mm}$ in length with a coarseness of $0.08 \mathrm{mg} / \mathrm{m}$ (Smook 2002).

\section{Contact Angle}

The contact angle test reflects the relative hydrophobicity of the straws, as shown in Table 5. Generally, a contact angle with water larger than $90^{\circ}$ forms with hydrophobic surfaces, and less than $90^{\circ}$ for hydrophilic surfaces (Zhao and Jiang 2018). The contact angle for the plastic samples was between $80^{\circ}$ and $98^{\circ}$. For all paper straws, the tested surface was considered hydrophobic because the angles were between $102^{\circ}$ and $125^{\circ}$. The surface of the paper straws was more hydrophobic than that of the plastic straws; this is an indication of surface treatment made on the paper. The untreated paper will have a lower contact angle, and will absorb the liquid, additionally reducing the contact angle noticeably 
over time (Moutinho et al. 2007; Tyagi et al. 2019). On the other hand, the plastic straws are not expected to take up any significant amount of water, as the paper straws might, and the contact angle considered constant with time.

Table 4. Paper Straw Fiber Quality Analysis (FQA)

\begin{tabular}{|c|c|c|c|}
\hline Sample ID & Paper1 (White) & Paper2 (Brown) & Paper3 (Color) \\
\hline Fiber Length $L_{\mathrm{n}}(\mathrm{mm})$ & $0.75 \pm 0.05$ & $0.72 \pm 0.01$ & $0.75 \pm 0.00$ \\
\hline Fiber Length $L_{\mathrm{w}}(\mathrm{mm})$ & $1.12 \pm 0.06$ & $0.92 \pm 0.01$ & $0.99 \pm 0.01$ \\
\hline Fines (\%) (Length Weighted) & $14.43 \pm 0.04$ & $8.21 \pm 0.53$ & $7.50 \pm 0.3$ \\
\hline Curl Index (Length Weighted) & $0.10 \pm 0.01$ & $0.11 \pm 0.00$ & $0.10 \pm 0.00$ \\
\hline Mean Width $(\mu \mathrm{m})$ & $20.3 \pm 0.85$ & $16.9 \pm 0.00$ & $17.2 \pm 0.00$ \\
\hline Kink Index $(1 / \mathrm{mm})$ & $1.6 \pm 0.01$ & $1.83 \pm 0.06$ & $1.75 \pm 0.06$ \\
\hline Coarseness $(\mathrm{mg} / \mathrm{m})$ & $0.08 \pm 0.00$ & $0.07 \pm 0.00$ & $0.07 \pm 0.01$ \\
\hline
\end{tabular}

Note: $L_{n}=$ Arithmetic average of fiber length and $L_{w}=$ weighted average fiber length

Table 5. Contact Angle for Paper and Plastic Straws (10 s)

\begin{tabular}{|c|c|c|}
\hline \multirow{2}{*}{ Sample ID } & \multicolumn{2}{|c|}{ Contact Angle $\left(^{\circ}\right)$} \\
\cline { 2 - 3 } & Inner Layer & Outer Layer \\
\hline Plastic1 & 85.10 & 84.66 \\
\hline Plastic2 & 95.38 & 88.56 \\
\hline Plastic3 & 80.62 & 79.42 \\
\hline Plastic4 & 89.26 & 97.95 \\
\hline Paper1 (White) & 112.83 & 132.29 \\
\hline Paper2 (Brown) & 124.65 & 102.72 \\
\hline Paper3 (Color) & 117.24 & 125.62 \\
\hline
\end{tabular}

\section{Dry Tensile Strength}

The tensile strength was measured for the plastic and paper straws, Tables 6 and 7 . Because of the inherent difference between these two materials, a fair comparison between the tensile properties was established using the specific strength and calculated by dividing the tensile strength by the density of the respective material. In this manner, the paper straws had a similar value between them, but the value changed considerably for the plastic straws. However, the paper straws had a higher specific strength with the exception of one of the plastic samples.

\section{Fold Endurance}

The fold endurance test determined the capacity of the straw to withstand repeated bending. The plastic straws offered a considerably higher resistance to this stress (Table 6). However, the paper straws were strong enough to resist typical usage and were unbroken after being bent multiple times (Table 7). 
Table 6. Mechanical Measurements for the Plastic Straws. Tested under standard TAPPI conditions $\left(23^{\circ} \mathrm{C}\right.$ and $50 \%$ relative humidity $\left.(\mathrm{RH})\right)$

\begin{tabular}{|c|c|c|c|c|c|}
\hline Plastic & Plastic1 & $\begin{array}{c}\text { Plastic2 } \\
\text { (Normal) }\end{array}$ & $\begin{array}{c}\text { Plastic2 } \\
\text { (Flexible } \\
\text { Zone) }\end{array}$ & Plastic3 & Plastic4 \\
\hline Load at Break (N) & 192 & 94 & 99 & 164 & 212 \\
\hline $\begin{array}{c}\text { Tensile Strength } \\
(\mathrm{MPa})\end{array}$ & 47.98 & 15.58 & 16.57 & 27.44 & 14.11 \\
\hline $\begin{array}{c}\text { Specific Strength } \\
(\mathrm{KN} \times \mathrm{m} / \mathrm{Kg})\end{array}$ & 56.08 & 18.22 & 19.38 & 33.78 & 19.99 \\
\hline Stretch (\%) & 1226.5 & 953.9 & 996.0 & 1279.0 & 1262.9 \\
\hline $\begin{array}{c}\text { Young's Modulus } \\
(\mathrm{MPa})\end{array}$ & 850.93 & 242.20 & 71.67 & 457.55 & 256.11 \\
\hline Stiffness (kN/m) & 709.11 & 201.83 & 59.73 & 381.30 & 320.13 \\
\hline Fold Endurance & $>5000$ & $>5000$ & $>5000$ & $>5000$ & $>5000$ \\
\hline
\end{tabular}

Table 7. Mechanical Measurements for the Paper Straws. Tested under standard TAPPI conditions $\left(23^{\circ} \mathrm{C}\right.$ and $50 \%$ relative humidity $\left.(\mathrm{RH})\right)$

\begin{tabular}{|c|c|c|c|}
\hline Paper & Paper1 (White) & Paper2 (Brown) & Paper3 (Color) \\
\hline Load at Break $(\mathrm{N})$ & 99.97 & 113.10 & 132.90 \\
\hline Tensile Strength $(\mathrm{kN} / \mathrm{m})$ & 10.00 & 11.31 & 13.29 \\
\hline $\begin{array}{c}\text { Specific Strength } \\
(\mathrm{KN} \times \mathrm{m} / \mathrm{Kg})\end{array}$ & 33.53 & 39.13 & 42.62 \\
\hline Stretch $(\%)$ & 3.7 & 4.0 & 4.1 \\
\hline Stiffness $(\mathrm{kN} / \mathrm{m})$ & 1219 & 1252 & 1285 \\
\hline Fold Endurance & 2582 & 1985 & 1681 \\
\hline
\end{tabular}

Figure 1 shows the plots of the strongest plastic and paper straws during the tensile test and displays the expected behavior of these types of polymeric materials.

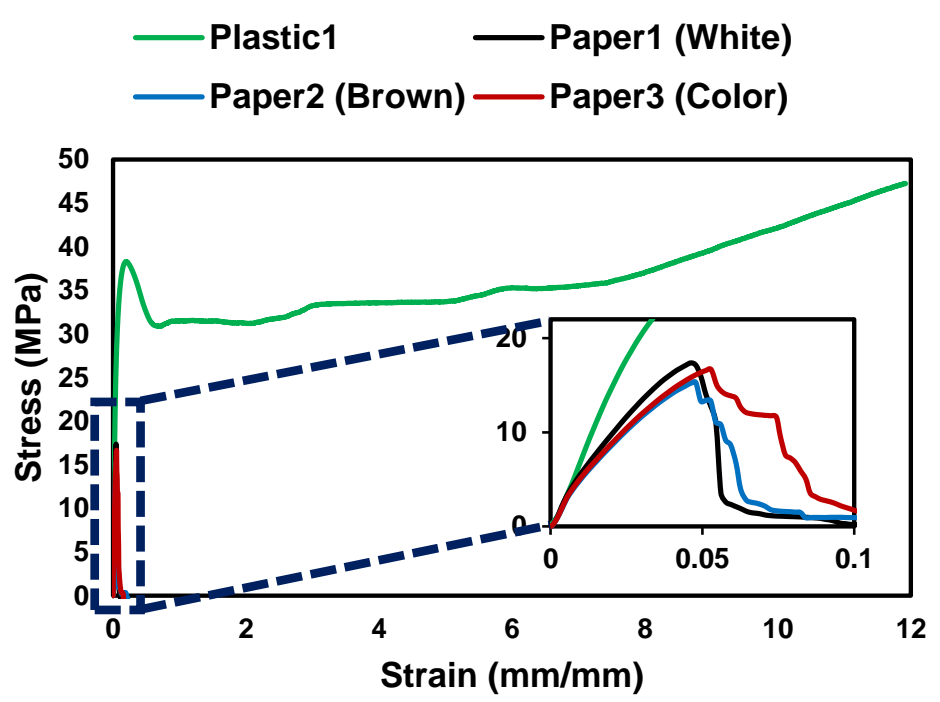

Fig. 1. Average tensile strength curves for paper and plastic straws; strongest plastic (plastic1) and paper1, paper2, and paper3. Enlargement of range to $0.1 \mathrm{~mm} / \mathrm{mm}$. 
Overall, the plastic tended to be stronger than the paper. The force needed to break the paper samples was $60 \%$ of the force needed to break the plastic straw, and the plastic straws could stretch roughly ten times or more before failure. In addition, the paper straws failed at $3.6 \%$ to $4.1 \%$ of strain, and the paper was stiffer than the plastic.

Figure 1 shows a typical tensile curve for polymers (green trend), with a Hookean or elastic region with a linear response (Young's modulus) of strain and increasing stress. The tensile yield strength was the first point where the linear trend ceased, and the plastic deformation started. The ultimate stress was the reported tensile strength and is the maximum load the material can stand before it breaks, divided by the initial transversal area.

\section{Axial Compression}

Table 8 shows the compressive strength for the plastic and paper straws for the axial configuration. The Paper3 straws achieved the highest compressive strength of the paper straws, but when compared with plastic, the paper could only withstand half of the force of the strongest plastic straw.

Table 8. Dry Axial Compressive Strength for Plastic and Paper

\begin{tabular}{|c|c|c|}
\hline Material & Sample ID & Compressive Strength (MPa) \\
\hline \multirow{4}{*}{ Plastic } & Plastic1 & 21.60 \\
\cline { 2 - 3 } & Plastic2 & 11.97 \\
\cline { 2 - 3 } & Plastic3 & 17.86 \\
\cline { 2 - 3 } & Plastic4 & 15.85 \\
\hline \multirow{3}{*}{ Paper } & Paper1 (White) & 9.26 \\
\cline { 2 - 3 } & Paper2 (Brown) & 7.96 \\
\cline { 2 - 3 } & Paper3 (Color) & 9.99 \\
\hline
\end{tabular}

Figure 2 shows the strongest of the plastic straws in contrast with the three brands of paper straws. The plastic cylindrical structure presented a narrower peak and the highest compression stress before it collapsed. In contrast, the paper showed a broader curve and reached the maximum load at a higher strain before it failed.

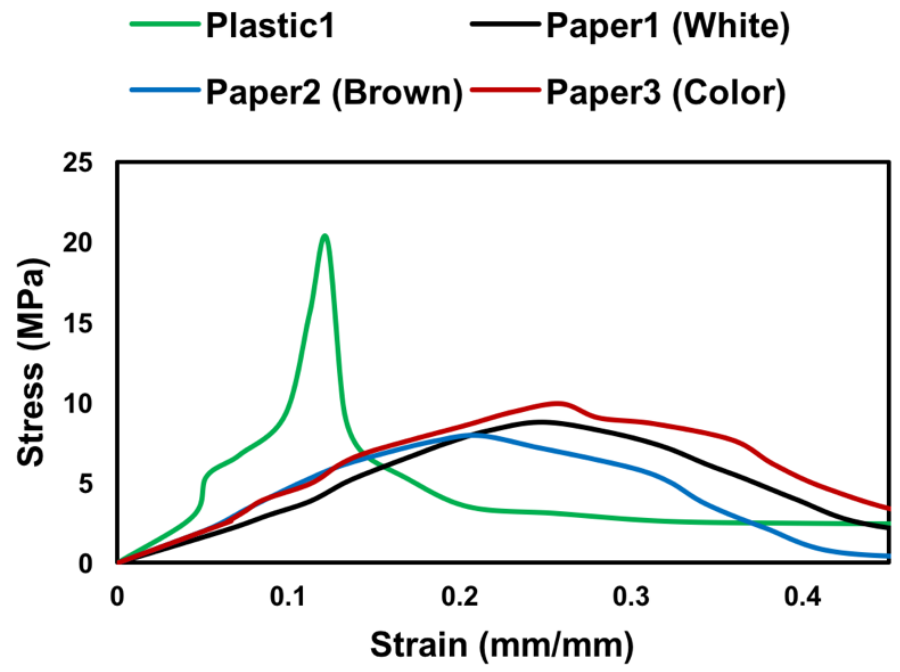

Fig. 2. Average compressive strength curves in the axial direction for plastic straws and the three brands of paper straws 


\section{Radial Compression}

The results of the radial configuration compressive strength are shown in Table 9. The paper straws exhibited more strength and a higher modulus than the plastic straws. The plastic deformed more easily, with more obvious elastic (reversible deformation) behavior. People often enjoy this property, as they sometimes like to repeatedly bite the straw and have it come back to its original state. This reversible deformation is not as likely with paper straws.

Table 9. Dry Radial Compressive Strength for Plastic and Paper Straws

\begin{tabular}{|c|c|c|c|c|}
\hline Material & Sample & $\begin{array}{c}\text { Maximum } \\
\text { Load (N) }\end{array}$ & $\begin{array}{c}\text { Compressive } \\
\text { Strength (kPa) }\end{array}$ & $\begin{array}{c}\text { Young's Modulus } \\
(\mathrm{kPa})\end{array}$ \\
\hline \multirow{4}{*}{ Plastic } & Plastic1 & 29.67 & 39.56 & 92.28 \\
\cline { 2 - 5 } & Plastic2 & 13.93 & 19.35 & 51.19 \\
\cline { 2 - 5 } & Plastic2 (Flexible Zone) & 22.13 & 40.09 & 110.01 \\
\cline { 2 - 5 } & Plastic3 & 12.09 & 21.89 & 97.52 \\
\cline { 2 - 5 } & Plastic4 & 35.97 & 35.97 & 83.24 \\
\hline \multirow{3}{*}{ Paper } & Paper1 (White) & 8.75 & 124.75 & 517.25 \\
\cline { 2 - 5 } & Paper2 (Brown) & 6.00 & 83.00 & 438 \\
\cline { 2 - 5 } & Paper3 (Color) & 9.50 & 132.00 & 776.5 \\
\hline
\end{tabular}

Paper2 (Brown) displayed the lowest strengths for both the axial and radial configurations. The axial configuration had a more considerable load tolerance than the radial configuration due to a geometrical configuration that allows an even distribution of the stress through the entire structure.

Figure 3 shows the radial compression curves of the plastic and paper straws. The transition between the elastic and plastic regions was not easy to distinguish in the plastic curve but was more easily shown in the paper curve. This means that the plastic acted as an elastic material without the plastic region for the strain tested. In addition, the paper could not recover the initial geometry of the material after the test, as did the plastic samples.

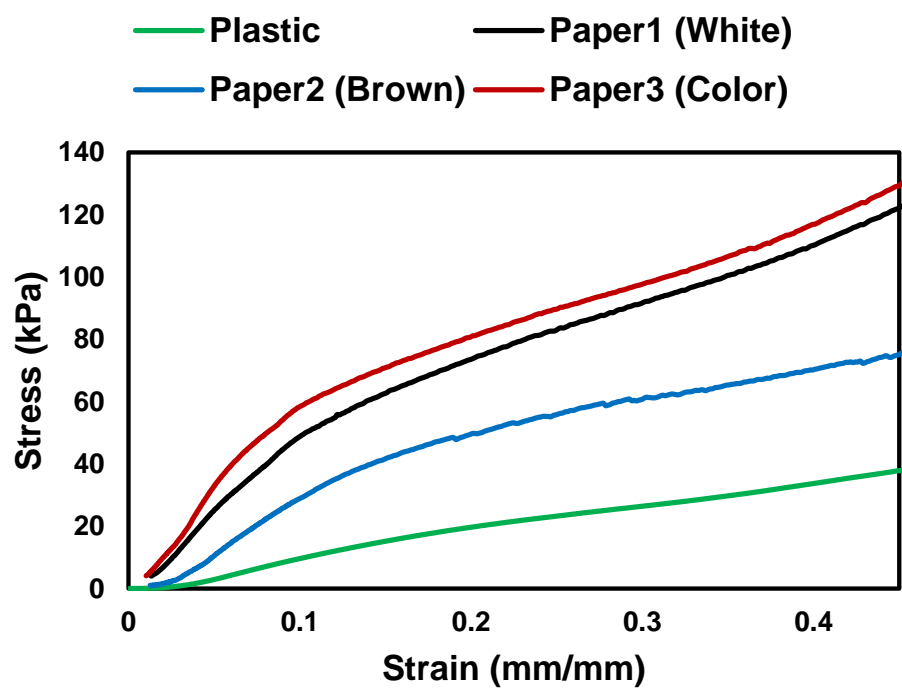

Fig. 3. Average compressive strength curves in the radial direction for plastic straws and the three brands of paper straws 


\section{Weight Gain for Different Liquids}

The first part of the longevity test was to measure how much liquid the straws in the test conditions retained as a function of time. Figure 4 shows the weight gain of the straws due to water absorption versus time at room temperature. The weight gain increased at a high rate for the first $20 \mathrm{~min}$, and then at a slower rate after that. Plastic straws showed negligible weight gain in all cases.

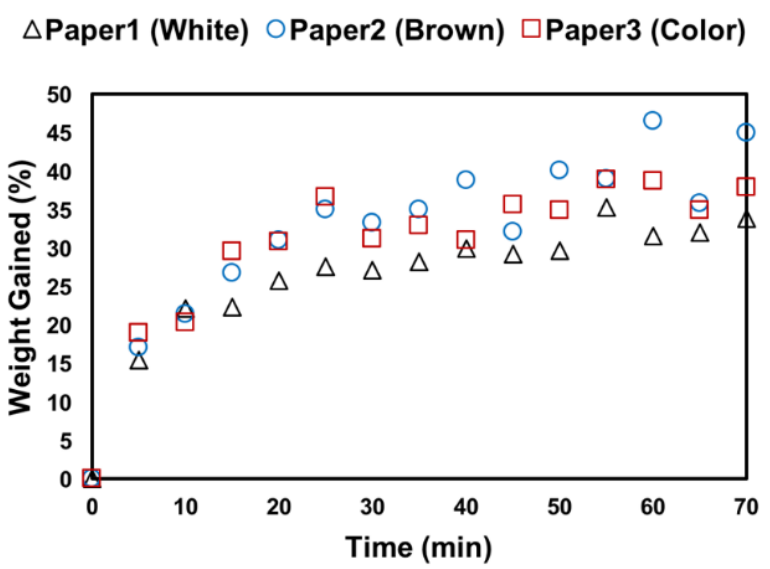

Fig. 4. Weight gain for paper straws in water at $21^{\circ} \mathrm{C}$ in 5 min intervals

$\square$ lce Coke $\Delta$ lce Water Olce Tea

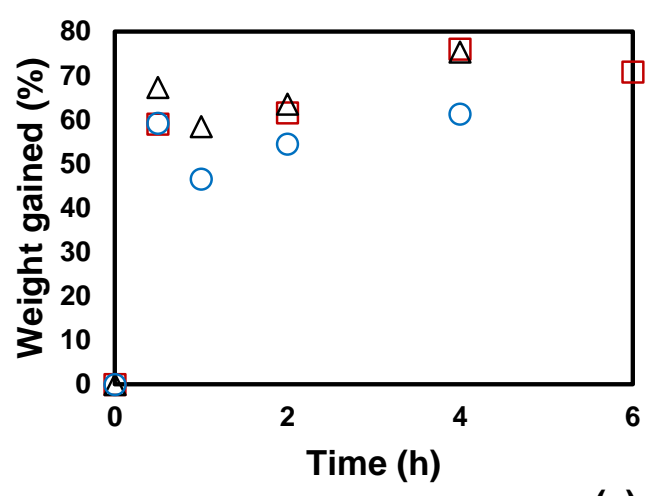

$\square$ lce Coke $\Delta$ lce Water Olce Tea

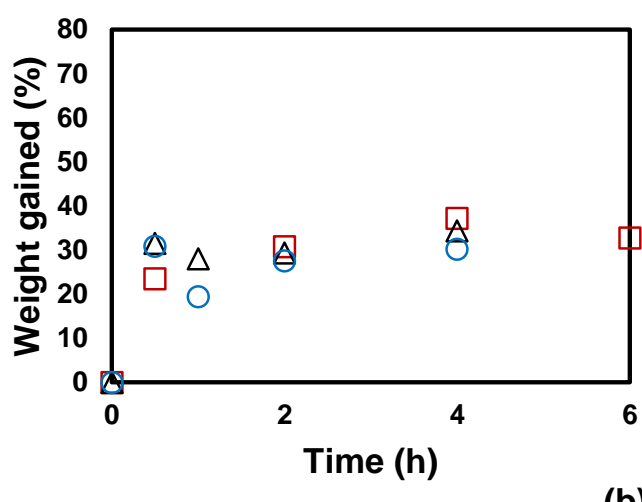

(a)

(b)

$\square$ Ice Coke $\Delta$ Ice Water Olce Tea

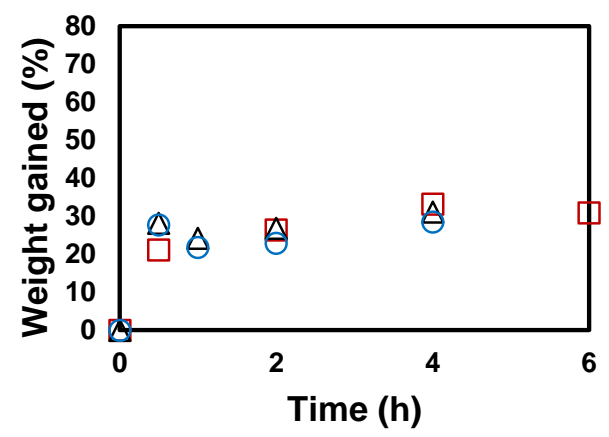

(c)

Fig. 5. Weight gained for (a) Paper1 (White), (b) Paper2 (Brown), and (c) Paper3 (Color) in three different beverages with an initial temperature of $0^{\circ} \mathrm{C}$ 
Figure 5 shows the weight gain as a percentage for Paper1 (White) (Fig. 5a), Paper2 (Brown) (Fig. 5b), and Paper3 (Color) (Fig. 5c) for some common beverages. This test was performed using the same initial temperature and liquid height in three different but common cold beverages: water, a carbonated beverage (Coke), and sweet tea. The most noticeable difference was between paper straw types rather than liquids. The Paper1 (White) straws gained up to $75 \%$ of their weight after four h of testing, while the other two brands only gained approximately $30 \%$ each. These results suggest that the brand of Paper1 (White) lacked the coating or protective material or had less internal sizing than did the other paper straws.

\section{Weight Gain for Different Temperatures}

Similarly, the three brands of paper straws were tested using water at three different temperatures (i.e., $0{ }^{\circ} \mathrm{C}, 21{ }^{\circ} \mathrm{C}$, and $48^{\circ} \mathrm{C}$ ). Paper1 (White) retained more liquid than the other paper straws. For Paper2 and Paper3 straws, the weight gain was higher for the higher liquid temperature, as expected. However, for Paper1 the opposite was true (Figure $6)$.
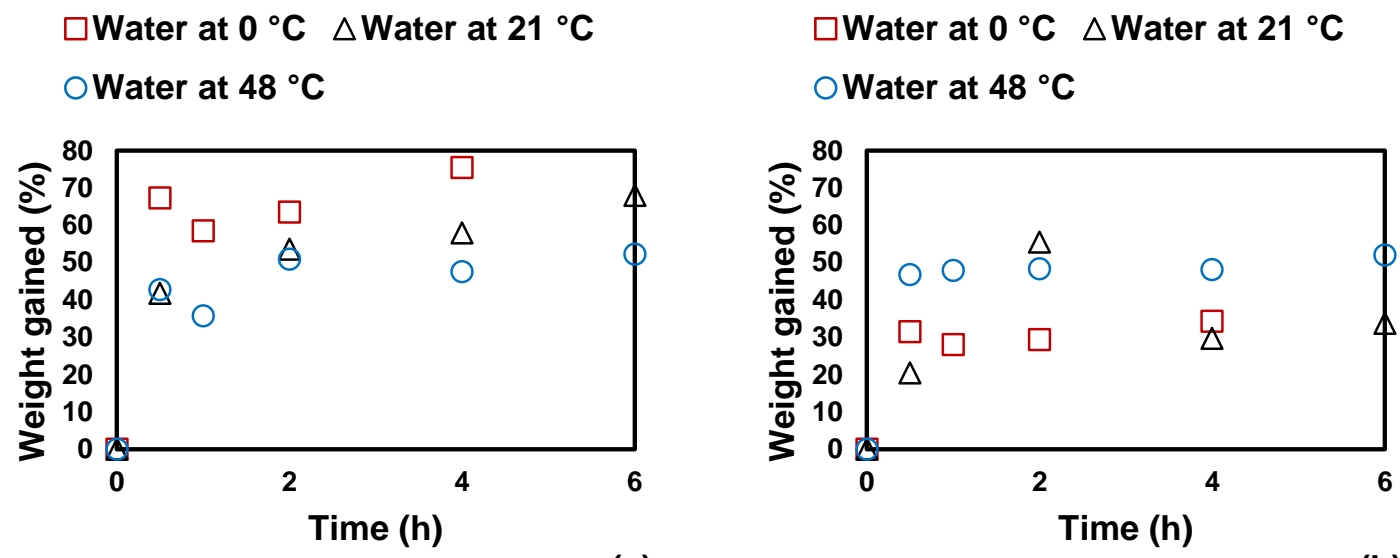

(a)

(b)

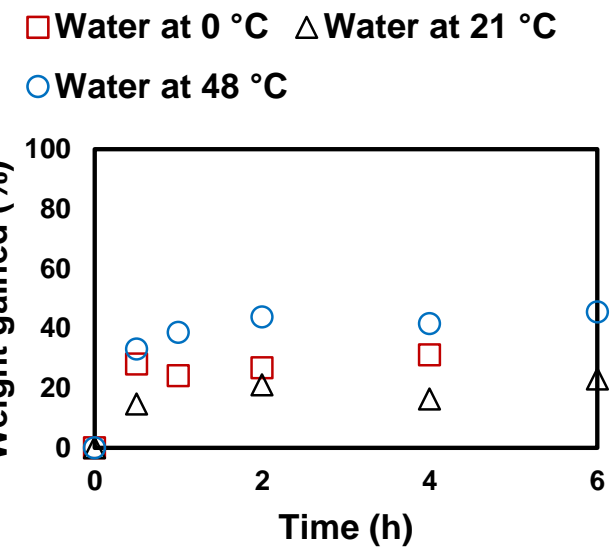

(c)

Fig. 6. Weight gained for (a) Paper1 (White), (b) Paper2 (Brown), and (c) Paper3 (Color) in water at three different initial temperatures 


\section{Effects of the Paper Straw and Liquid Interactions}

A concern for using paper straws is how the appearance of the liquid and the straws are affected by the interaction between them. The appearance of the paper straws after 30 min and $6 \mathrm{~h}$ after being in contact with Coke is shown in Table 10. It is observed that the paper straws all showed a distinct darkening due to the absorption of the Coke.

Table 10. Paper Straw Appearance After Longevity Test

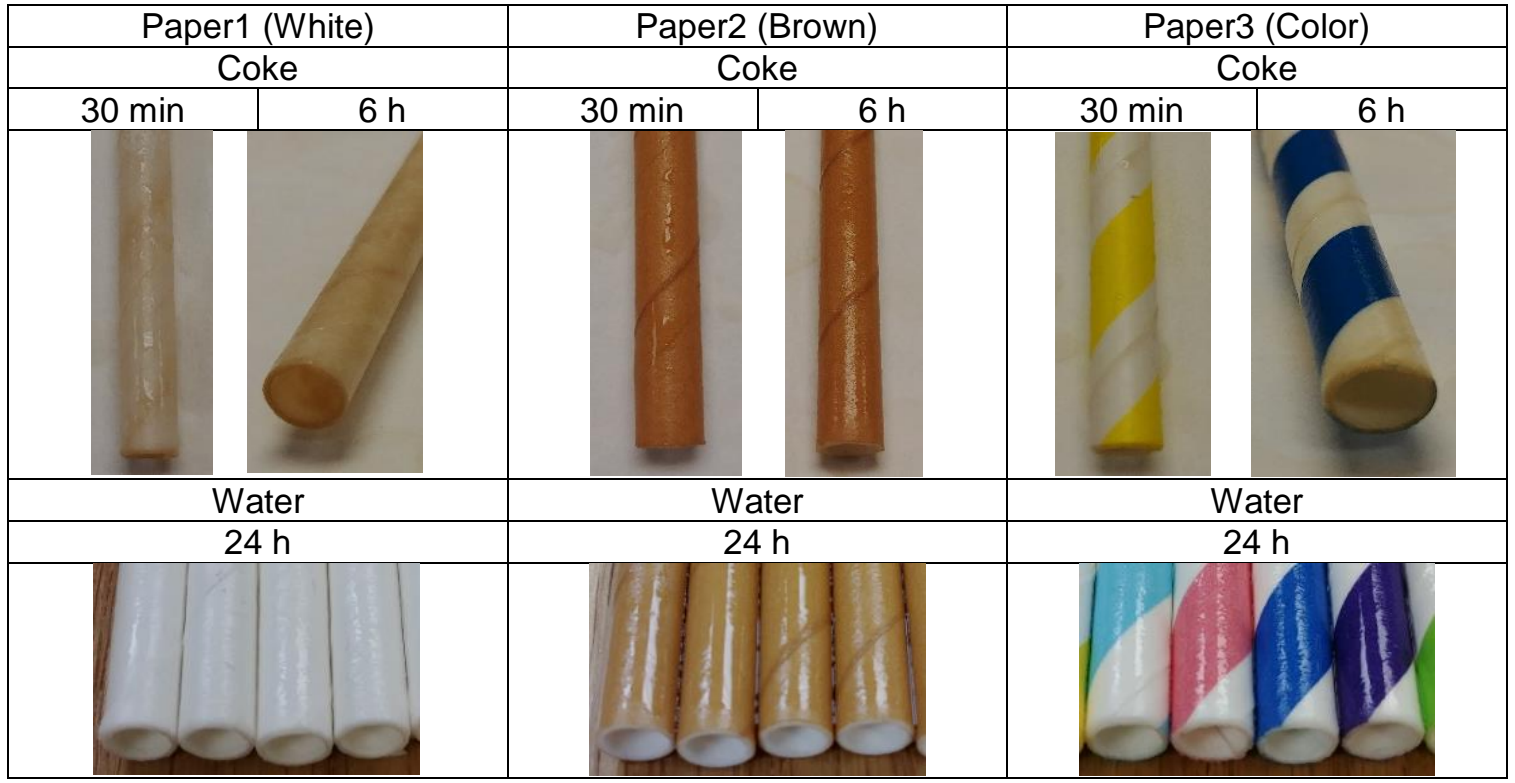

To investigate whether the straws released any material/particles during the contact with the liquids, the turbidity of the water was measured after 6 and $24 \mathrm{~h}$ of the straws being in contact with the water. The appearance of the straws after $24 \mathrm{~h}$ in water is also shown in Table 10. The results indicated that the paper straws acquired the color of the liquid, but the straws did not visually change the appearance of the liquid and did not release any solids into the liquid, even under periods considerably larger than the average for these single-use disposable materials.

\section{Material Transfer from Straw to Liquid Measured by Turbidity}

The turbidity values obtained from the paper straws being in contact with water for $24 \mathrm{~h}$ are shown in Table 11. The liquid was completely clear to the human eye with an average value of $0.56 \mathrm{FNU}$ (formazin nephelometric unit).

Table 11. Turbidity Measurement after $24 \mathrm{~h}$ of Direct Contact between Water and Paper Straws

\begin{tabular}{|c|c|}
\hline Liquid & Turbidity (FNU) \\
\hline Drinking Water & 0 \\
\hline Water - Paper1 (White) & $0.52 \pm 0.11$ \\
\hline Water - Paper2 (Brown) & $0.63 \pm 0.12$ \\
\hline Water - Paper3 (Color) & $0.53 \pm 0.09$ \\
\hline
\end{tabular}




\section{Compression of Paper Straws Exposed to Liquid}
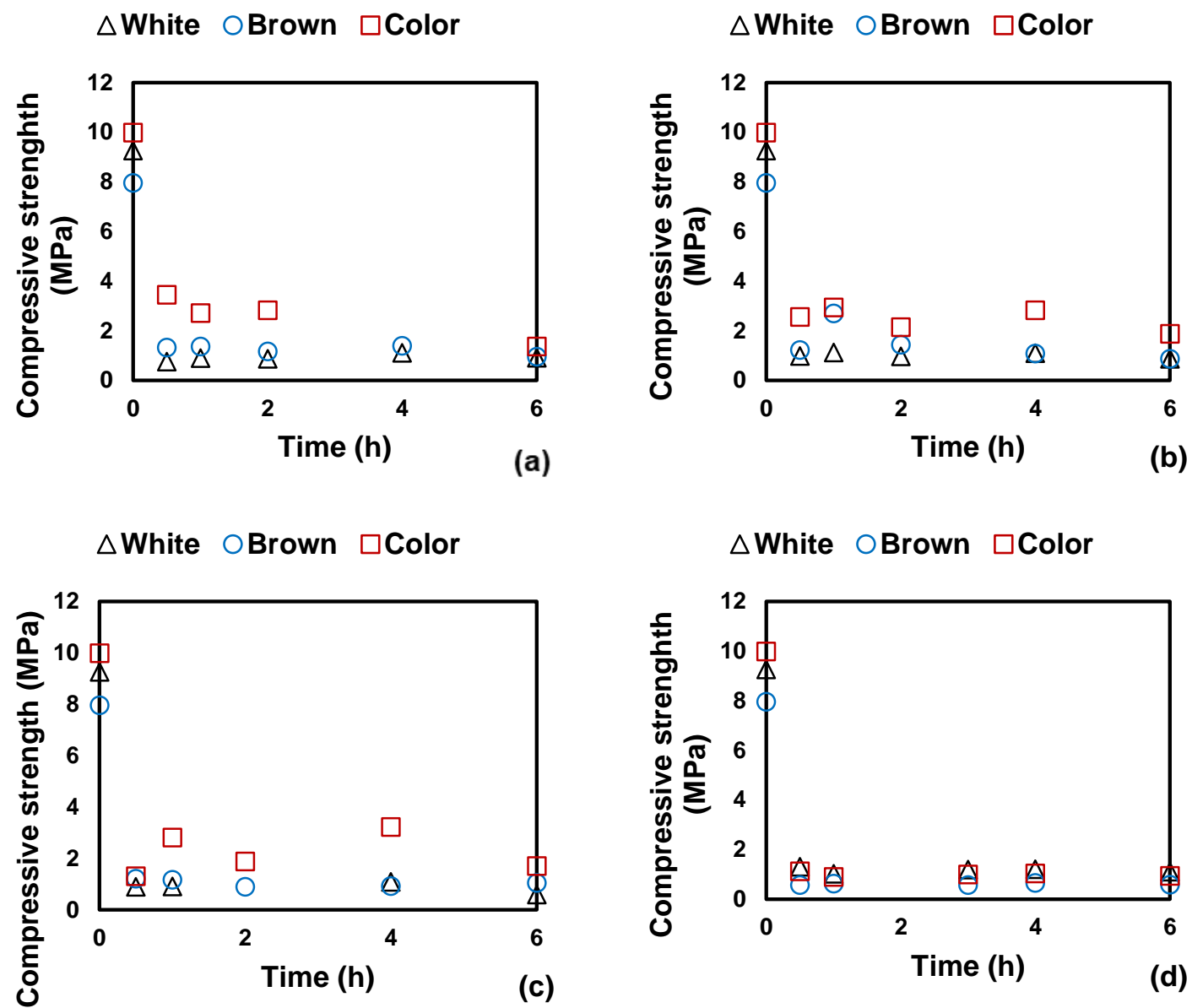

$\triangle$ White OBrown $\square$ Color

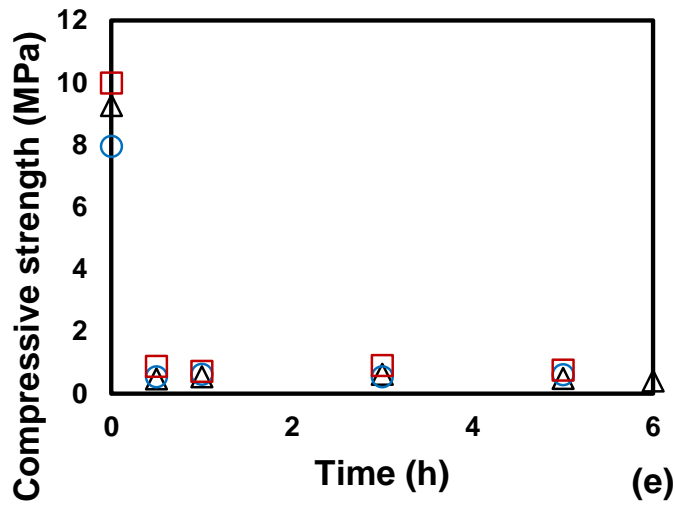

Fig. 7. Axial compressive strength vs. time for straws immersed in: (a) Coke at an initial temperature of $0{ }^{\circ} \mathrm{C}$ (temperature remained at $0{ }^{\circ} \mathrm{C}$ for $3 \mathrm{~h}$, and after $6 \mathrm{~h}$, the temperature reached $15^{\circ} \mathrm{C}$ ); (b) water at an initial temperature of $0^{\circ} \mathrm{C}$ (temperature remained at $0{ }^{\circ} \mathrm{C}$ for $3 \mathrm{~h}$, and after $6 \mathrm{~h}$, the temperature reached $15^{\circ} \mathrm{C}$ ); (c) water at an initial temperature of $21^{\circ} \mathrm{C}$; (d) water at an initial temperature of $48^{\circ} \mathrm{C}$; and (e) water at an initial temperature of $82^{\circ} \mathrm{C}$ 
To be seen by the naked eye, the value must be at least 4 FNU (World Health Organization 2011), 55 FNU for a cloudy suspension, and 515 FNU for an opaque suspension (Fondriest Environmental, Inc. 2014). The values indicated that no relevant amount of solid migrated in the liquid. Considering that drinking water needs to have a value under $10 \mathrm{FNU}$ to be acceptable, the paper straws did not noticeably contaminate the liquids after $24 \mathrm{~h}$ of direct contact (Minnesota Pollution Control Agency 2008; Muthuraman and Sasikala 2014).

\section{Axial compression}

In this section, the second part of the longevity test is discussed. The compressive tests of the paper straws in wet conditions as a function of time, with an initial liquid temperature and a fixed liquid height, was conducted. The axial and radial configurations were evaluated.

Figure $7 \mathrm{a}$ shows the compressive strength of the paper straws relative to the dry condition (point zero) as a function of time. The strength decreases by about $80 \%$ within the first $30 \mathrm{~min}$ and then retained that level throughout the rest of the test. The reduction of force was approximately $90 \%$ in some cases. The Paper3 (Color) straws remained as the brand with the highest compressive strength at every condition, in all liquids tested and at all temperatures. As shown in Figs. $7 \mathrm{a}$ and $7 \mathrm{~b}$, when the Coke and water were at the same initial temperature $\left(0^{\circ} \mathrm{C}\right)$, there was no relevant difference in compressive strength between the two beverages. As shown in Figs. $7 \mathrm{~b}$ through $7 \mathrm{e}$, initial temperature increases reduced the compressive strength of the paper straws even further. Several samples completely lost their structural integrity in the water at $82{ }^{\circ} \mathrm{C}$, making the compression test not possible for these samples.

\section{Radial compression}

The longevity tests of the paper straw compressive strength in the axial direction of the straws are discussed in this section. The results for water at $0{ }^{\circ} \mathrm{C}$ and $21{ }^{\circ} \mathrm{C}$, and Coke at $0{ }^{\circ} \mathrm{C}$ after two $\mathrm{h}$ in direct contact with the liquid are shown in Tables 12 to 14 for the paper straws.

Table 12. Radial Compression Strength for Paper1 (White) Straws out of the box ${ }^{*}$ and after $2 \mathrm{~h}$ immersed in liquid

\begin{tabular}{|c|c|c|c|}
\hline Liquid & Load $(\mathrm{N})$ & Compressive Strength $(\mathrm{kPa})$ & Young's Modulus $(\mathrm{kPa})$ \\
\hline Out of the box & 8.75 & 124.75 & 517.25 \\
\hline Water at $21^{\circ} \mathrm{C}$ & 3.77 & 10.48 & 28.00 \\
\hline Ice Water & 4.00 & 11.11 & 29.00 \\
\hline Ice Coke & 3.80 & 10.55 & 27.00 \\
\hline
\end{tabular}

${ }^{*}$ Out of the box refers to the results of Table 9, the compressive test of the straws before contact with any liquid

The Paper3 (Color) straws remained the strongest in terms of the load they could sustain. Similar to the axial configuration, the paper straws lost $80 \%$ to $90 \%$ of their compressive strength after exposure to the liquids for $30 \mathrm{~min}$. 
Table 13. Radial Compression Strength for Paper2 (Brown) Straws out of the box* and after $2 \mathrm{~h}$ immersed in liquid

\begin{tabular}{|c|c|c|c|}
\hline Liquid & Load $(\mathrm{N})$ & $\begin{array}{c}\text { Compressive } \\
\text { Strength }(\mathrm{kPa})\end{array}$ & $\begin{array}{c}\text { Young's Modulus } \\
(\mathrm{kPa})\end{array}$ \\
\hline Out of the box & 6.00 & 83.00 & 438 \\
\hline Water at $21^{\circ} \mathrm{C}$ & 5.50 & 15.29 & 41 \\
\hline Ice Water & 4.81 & 13.38 & 33 \\
\hline Ice Coke & 5.09 & 14.13 & 39 \\
\hline
\end{tabular}

${ }^{*}$ Out of the box refers to the results of Table 9 , the compressive test of the straws before contact with any liquid

Table 14. Radial Compression Strength for Paper3 (Color) Straws out of the box* and after $2 \mathrm{~h}$ immersed in liquid

\begin{tabular}{|c|c|c|c|}
\hline Liquid & Load $(\mathrm{N})$ & Compressive Strength $(\mathrm{kPa})$ & Young's Modulus $(\mathrm{kPa})$ \\
\hline Out of the box & 9.50 & 132.00 & 776.5 \\
\hline Water at $21^{\circ} \mathrm{C}$ & 12.00 & 33.33 & 92.0 \\
\hline Ice Water & 9.49 & 26.36 & 64.0 \\
\hline Ice Coke & 8.78 & 24.39 & 53.0 \\
\hline
\end{tabular}

${ }^{*}$ Out of the box refers to the results of Table 9, the compressive test of the straws before contact with any liquid

The longevity test was also performed with water at different initial temperatures, as shown in Fig. 8.

The results show how the compressive strength was reduced by $80 \%$ to $85 \%$ after $30 \mathrm{~min}$ and remained in this range during the remainder of the test. Like the axial configuration, a higher temperature negatively affected the radial compressive strength and further reduced the results to close to $90 \%$ of the dry value.
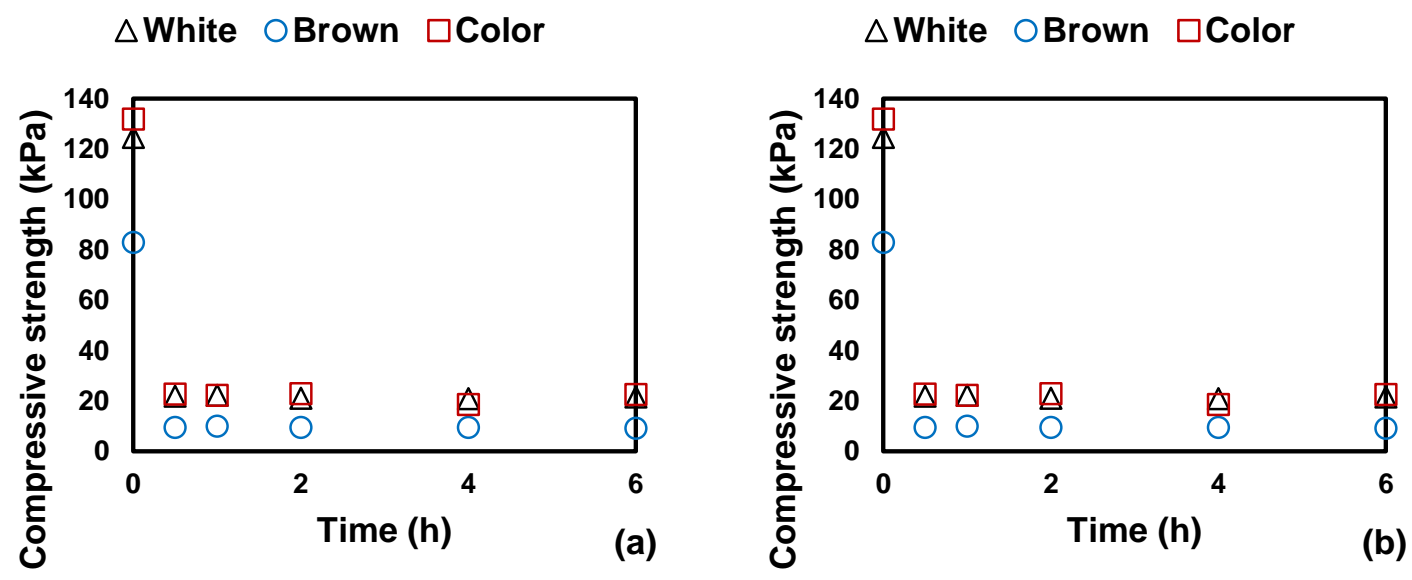

Fig. 8. Radial compressive strength vs. time for straws immersed in water at (a) an initial temperature of $48^{\circ} \mathrm{C}$ and (b) an initial temperature of $82^{\circ} \mathrm{C}$ 


\section{CONCLUSIONS}

1. The paper straws were made mainly of hardwood fibers and had been treated to increase their hydrophobicity. Their surfaces formed initial contact angles with water in the range of $100^{\circ}$ to $125^{\circ}$, indicative of hard sized paper surfaces.

2. The paper straws experienced weight gain almost immediately after exposure to liquids and gained weights of $30 \%$ to $50 \%$ within $60 \mathrm{~min}$.

3. The plastic straws were generally stronger than the paper straws in the dry state and did not gain weight when immersed in fluids. Plastic straws did not display any decreases in mechanical properties upon immersion in liquids

4. Paper straws displayed higher compressive strength in the radial configuration under dry conditions than the plastic straws; however, the plastic straws returned to the original shape after release of the force, and the paper straws did not.

5. The type of fluid did not have a noticeable impact on the weight gain or wet strength of the paper straws.

6. An increase in the liquid temperature increased the weight gained for the paper straws and reduced the wet strength.

7. The paper straws did not release appreciable particle solids into the liquids as evidenced by liquid turbidity measurements before and after exposure to the paper straws.

8. None of the paper straws evaluated had considerable stability after $30 \mathrm{~min}$ in liquids, losing $80 \%$ to $90 \%$ of their strength within $30 \mathrm{~min}$ of exposure to liquid.

9. Tracking of the time-dependent weight gain and compressive strength of paper straws under immersion of liquids was an insightful way to evaluate paper straw product performance.

\section{ACKNOWLEDGMENTS}

The authors are thankful to Dr. Ved Naithani for assisting in conducting the FQA testing.

\section{REFERENCES CITED}

Aardvark. (2019). "AArdvark Straws," <https://www.aardvarkstraws.com/ecoflex-paperstraws>.

Andrady, A. L. (2011). "Microplastics in the marine environment," Marine Pollution Bulletin 62(8), 1596-1605. DOI: 10.1016/j.marpolbul.2011.05.030

ASTM D695-15 (2015). "Standard test method for compressive properties of rigid plastics," ASTM International, West Conshohocken, PA.

ASTM D882-12 (2012). "Standard test method for tensile properties of thin plastic sheeting," ASTM International, West Conshohocken, PA.

ASTM D2412-11 (2018). "Standard test method for determination of external loading characteristics of plastic,” ASTM International, West Conshohocken, PA. 
ASTM D6855-17 (2017). "Standard test method for determination of turbidity below 5 NTU in static mode," ASTM International, West Conshohocken, PA.

British Broadcasting Corporation (BBC) (2018). "Most paper straws are made in Asia but now UK firms are starting to produce them again," $B B C$, (https://www.bbc.com/news/av/business-45740772/most-paper-straws-are-made-inasia-but-now-uk-firms-are-starting-to-produce-them-again), Accessed 3 Feb 2019.

Brueck, H. (2018). "The real reason why so many cities and businesses are banning plastic straws has nothing to do with straws at all," Business Insider, (https://www.businessinsider.com/plastic-straw-ban-why-are-there-so-many-2018-7), Accessed 3 Feb 2019.

Chokshi, N. (2018). "How a 9-year-old boy's statistic shaped a debate on straws," The New York Times, (https://www.nytimes.com/2018/07/19/business/plastic-straws-banfact-check-nyt.html), Accessed 4 Feb 2019.

Danovich, T. (2018). "Why people with disabilities want bans on plastic straws to be more flexible," <https:/www.npr.org/sections/thesalt/2018/07/11/627773979/whypeople-with-disabilities-want-bans-on-plastic-straws-to-be-more-flexible $>$

Eagle, L., Hamann, M., and Low, D. R. (2016). "The role of social marketing, marine turtles and sustainable tourism in reducing plastic pollution," Marine Pollution Bulletin 107(1), 324-332. DOI: 10.1016/j.marpolbul.2016.03.040

Fondriest Environmental, Inc. (2014). "Measuring turbidity, TSS, and water clarity," Fondriest Environmental Learning Center, (https://www.fondriest.com/environmental-measurements/measurements/measuringwater-quality/turbidity-sensors-meters-and-methods/), Accessed 4 Feb 2019.

Geyer, R., Jambeck, J. R., and Law, K. L. (2017). "Production, use, and fate of all plastics ever made," Science Advances 3(7), 25-29. DOI: 10.1126/sciadv.1700782

Hach (2019). "What is the difference between the turbidity units NTU, FNU, FTU, and FAU? What is a JTU?," (https://support.hach.com/app/answers/answer_view/a_id/1000336/ /what-is-thedifference-between-the-turbidity-units-ntu $\% 2 \mathrm{C}$-fnu $\% 2 \mathrm{C}$-ftu $\% 2 \mathrm{C}$-and-fau $\% 3 \mathrm{~F}$ what>), Accessed 4 Feb 2019.

Haetrakul, T., Munanansup, S., Assawawongkasem, N., and Chansue, N. (2009). “A case report: Stomach foreign object in whaleshark (Rhincodon typus) stranded in Thailand," in: Proceedings of the 4th International Symposium on SEASTAR 2000 and Asian Bio-logging Science (The 8th SEASTAR 2000 workshop), Phuket, Thailand, pp. 83-85.

Minnesota Pollution Control Agency (2008). Turbidity: Description, Impact on Water Quality, Sources, Measures - A General Overview, Minnesota Pollution Control Agency, St. Paul, MN, USA.

Minter, A. (2018). "Plastic straws aren't the problem," Bloomberg, (https://www.bloomberg.com/opinion/articles/2018-06-07/plastic-straws-aren-t-theproblem), Accessed 8 Feb 2019.

Moutinho, I., Figueiredo, M., and Ferreira, P. (2007). "Evaluating the surface energy of laboratory-made paper sheets by contact angle measurements," Tappi Journal, (6), 26-32.

Muthuraman, G., and Sasikala, S. (2014). "Removal of turbidity from drinking water using natural coagulants," Journal of Industrial and Engineering Chemistry 20(4), 1727-1731. DOI: 10.1016/j.jiec.2013.08.023

Ocean Conservancy (2017). "Building a clean swell," Oceanconservancy.org, 
(https://oceanconservancy.org/wp-content/uploads/2018/07/Building-A-CleanSwell.pdf), Accessed 12 Feb 2019.

Purtill, C. (2018). "Ban plastic straws. Just don't use paper ones, because they're awful," Quartzy, (https://qz.com/quartzy/1324163/ban-plastic-straws-just-dont-use-paperones/), Accessed 20 Feb 2019.

Shah, A. A., Hasan, F., Hameed, A., and Ahmed, S. (2008). "Biological degradation of plastics: A comprehensive review," Biotechnology Advances 26(3), 246-265. DOI: 10.1016/j.biotechadv.2007.12.005

Simmonds, M. P. (2012). "Cetaceans and marine debris: The great unknown," Journal of Marine Biology 2012, Article ID 684279. DOI: 10.1155/2012/684279

Smith, E. (2017). "A brief history of the modern-day straw, the world's most wasteful commodity," Atlas Obscura, (https://www.atlasobscura.com/articles/straws-history), Accessed 20 Feb 2019.

Smook, G. A. (2002). Handbook for Pulp and Paper Technologists, Angus Wilde Publications Inc., Vancouver, Canada.

Sorensen, E., and Reinke, J. (2018). "Inside the only U.S. paper straw manufacturer," Industrial Equipment News, (https://www.ien.com/operations/video/21017274/insidethe-only-us-paper-straw-manufacturer), Accessed 25 Feb 2019.

Starbucks Stories (2018). "Starbucks and closed loop partners to develop recyclable, compostable cup solution," Starbucks Stories, (https://stories.starbucks.com/stories/2018/starbucks-and-closed-loop-to-developrecyclable-compostable-cup-solution/), Accessed 25 Feb 2019.

TAPPI T494 om-01 (2006). "Tensile properties of paper and paperboard (using constant rate of elongation apparatus)," TAPPI Press, Atlanta, GA.

TAPPI T511 om-02 (2008). "Folding endurance of paper (MIT tester)," TAPPI Press, Atlanta, GA.

Szymkowiak, J. (2018). “Guest Blog: Action on plastics shouldn't make life suck for disabled people," <https://www.greenpeace.org/canada/en/story/735/guest-blogaction-on-plastics-shouldnt-make-life-suck-for-disabled-people/>.

The Guardian (2018). "Starbucks to ditch plastic straws globally by 2020 to help environment," The Guardian, (https://www.theguardian.com/business/2018/jul/09/starbucks-eliminate-plasticstraws-globally-2020), Accessed 5 March 2019.

Tyagi, P., Lucia, L. A., Hubbe, M. A., and Pal, L. (2019). "Nanocellulose-based multilayer barrier coatings for gas, oil, and grease resistance," Carbohydrate Polymers, 206(15), 281-288. DOI: 10.1016/j.carbpol.2018.10.114.

Thompson, D. (2011). "The amazing history and the strange invention of the bendy straw," The Atlantic, (https://www.theatlantic.com/business/archive/2011/11/theamazing-history-and-the-strange-invention-of-the-bendy-straw/248923/), Accessed 10 Feb 2019.

TAPPI T271 om-07 (2012). "Fiber length of pulp and paper by automated optical analyzer using polarized light," TAPPI Press, Atlanta, GA.

TAPPI T402 sp-08 (2013). "Standard conditioning and testing atmospheres for paper, board, pulp, handhsheets, and related products," TAPPI Press, Atlanta, GA.

United Nations Environment Programme (UNEP) (2018). Single-use Plastics: A Roadmap for Sustainability, Economy Division of UNEP, Tsurumi-ku, Osaka, Japan.

Wootson, C. R. (2018). "Seattle becomes first major U.S. city to ban straws," The Washington Post, (https://www.washingtonpost.com/news/post- 
nation/wp/2018/07/01/seattle-becomes-first-major-u-s-city-to-banstraws/?noredirect=on\&utm_term=.dc9444785166), Accessed 10 March 2019.

World Health Organization (WHO) (2011). “Acceptability aspects: Taste, odour and appearance," Guidelines for Drinking-water Quality 38(3), 219-230.

Zhao, T., and Jiang, L. (2018). "Contact angle measurement of natural materials," Colloids and Surfaces B: Biointerfaces 161, 324-330. DOI:

10.1016/j.colsurfb.2017.10.056

Article submitted: April 14, 2019; Peer review completed: July 13, 2019; Revised version received: August 23, 2019; Accepted: August 24, 2019; Published: September 4, 2019. DOI: $10.15376 /$ biores. 14.4.8345-8363 